\title{
Brucellosis outbreak in Chouf district of Lebanon in 2009: a case-control study
}

\author{
L. Al-Shaar, ${ }^{1}$ M. Chaaya, ${ }^{1}$ N. Ghosn ${ }^{2}$ and Z. Mahfoud ${ }^{3}$
}

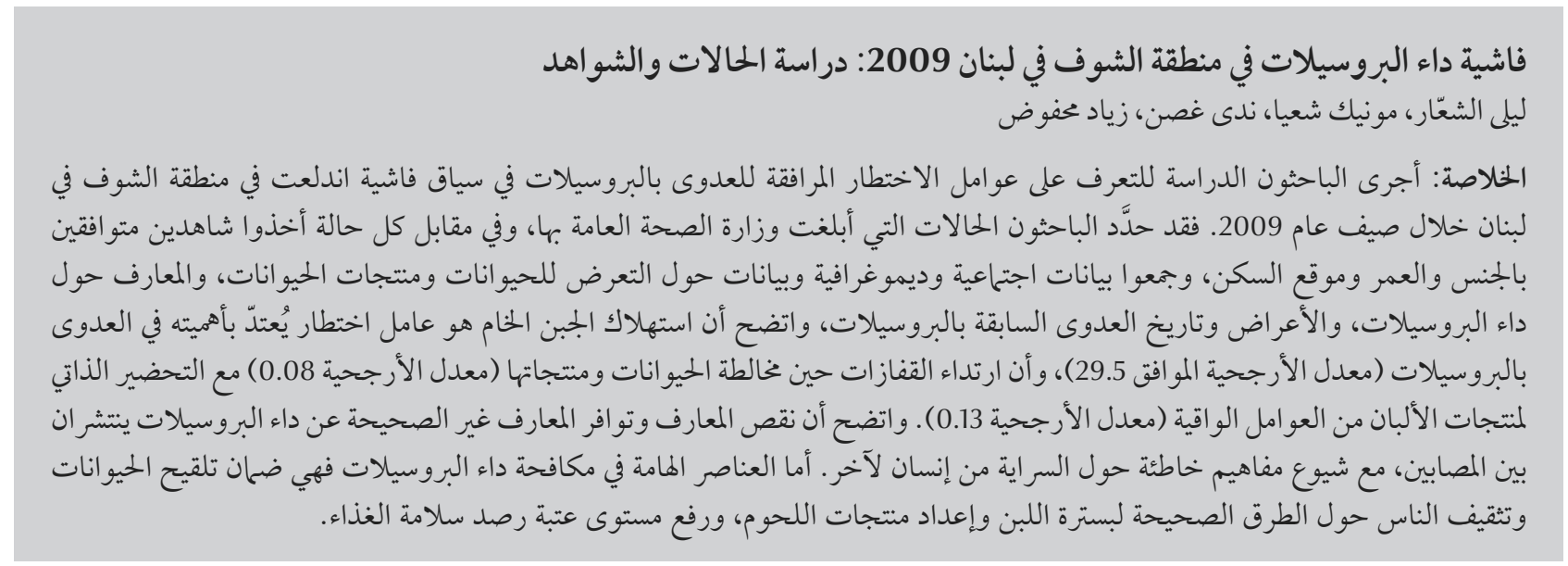

ABSTRACT A study was conducted to determine risk factors associated with brucellosis infection in an outbreak in Chouf district of Lebanon during summer 2009. Cases of brucellosis reported to the Ministry of Public Health were identified, and for each case 2 controls were matched by sex, age and residence. Sociodemographic data, exposure to animals and animal products, knowledge about brucellosis, symptoms and history of past brucellosis infections were collected. Consumption of raw cheese was a significant risk factor for contracting brucellosis (matched OR = 29.5), whereas wearing gloves when in contact with animals and animal products and self-preparing dairy products were protective factors ( $\mathrm{OR}=0.08$ and 0.13 respectively). Low and inaccurate knowledge about brucellosis was prevalent among subjects, with a common misconception about human-human transmission. Ensuring animal vaccination, educating people on correct ways of milk pasteurization and handling meat products, and elevating food safety monitoring threshold are key elements in controlling brucellosis.

\section{Flambée de brucellose dans le district de Chouf (Liban) en 2009 : étude cas-témoins}

RÉSUMÉ Une étude a été menée afin de déterminer les facteurs de risque associés à la brucellose au cours d'une flambée dans le district de Chouf (Liban) pendant l'été 2009. Des cas de brucellose notifiés au ministère de la Santé publique ont été identifiés, et pour chaque cas deux témoins ont été appariés pour l'âge, le sexe et le lieu de résidence. Les données sociodémographiques, les antécédents d'exposition aux animaux et aux produits destinés aux animaux, les connaissances sur la brucellose, les symptômes et les antécédents de brucellose ont été recueillis. La consommation de fromage cru était un facteur de risque important pour l'infection (OR apparié $=29,5$ ) tandis que le port de gants lors des contacts avec des animaux et des produits destinés aux animaux ainsi que la préparation des produits laitiers par la personne elle-même étaient des facteurs protecteurs $(O R=0,08$ et 0,13 respectivement). Des connaissances faibles et inexactes sur la brucellose étaient prévalentes chez les patients, et les idées fausses sur la transmission interhumaine étaient courantes. Assurer une vaccination animale, éduquer la population en ce qui concerne les bonnes méthodes de pasteurisation du lait et de manipulation des produits carnés, et relever les niveaux de suivi de la sécurité sanitaire des aliments sont des éléments clés de la lutte contre la brucellose. 


\section{Introduction}

Brucellosis is among the most widespread zoonotic diseases, being endemic in the Middle East, Mediterranean Europe, Western Asia, Africa and some South American countries $[1,2]$. It is transmitted to humans on consuming infected animal products such as raw dairy products and raw meat of cattle, goat and sheep, or when in direct contact with tissues and fluids of infected animals. Human-to-human transmission is extremely rare [2-4]. Brucellosis is considered a major animal-related occupational health hazard for dairy farmers, shepherds, animal husbandry and slaughterhouse workers, meat handlers and butchers, veterinarians and their assistants [5-7]. It constitutes a serious public health problem due to its economic impact on the animal livestock industry in terms of reproductive losses [8], as well as its debilitating health implications on humans due to its associated symptoms, which are sometimes misdiagnosed as malaria or typhoid fever [9]. Brucellosis can also cause complications such as spontaneous abortion and endocarditis, with a case fatality rate that varies from $<2 \%$ to $5 \%$ [2]. Chronicity can take different forms such as hepatitis, arthritis and inflammation of the optic nerve [2].

In 2008, an unpublished serosurveillance study by the Ministry of Agriculture in Lebanon revealed that one-third of a national random sample of herds were infected with Brucella spp., and that each infected herd contained around $10 \%$ infected animals. In Lebanon, brucellosis is also endemic in humans, with an annual incidence ranging between 3.5 and 9 cases per 100000 inhabitants from 1997 to October 2009 (Figure 1) [10]. It is one of the 37 mandatory notifiable diseases in the country. Health professionals usually report incident cases using a standardized reporting form to the epidemiological surveillance unit of the Ministry of Public Health
$(\mathrm{MOPH})$, where data are added to the national database. Consequently, alerts for outbreak detection are generated and verified on a weekly basis [11]. The only descriptive study on human brucellosis was conducted in 1997 on data reported to the epidemiological surveillance unit and showed no sex differences in occurrence, and a seasonal distribution related to the herds' birthing season [12]. Other studies by Lebanese researchers have provided clinical descriptions of brucellosis cases [13-17], while a genetic study highlighted the antimicrobial resistance of Brucella spp. isolates from cultured Lebanese dairy products [18]. Our study was therefore the first analytical study on human brucellosis in Lebanon.

The geographical distribution of brucellosis varies according to governorates, ranging from 0.99 cases per 100000 inhabitants in Beirut to 4.91 per 100000 in Nabatieh and 9.00 per 100000 in Beka'a [10]. Between 2001 and 2008, brucellosis cases in the Chouf district of Mount Lebanon governorate ranged from 1 to 6 cases per year, or
0.6-3.6 cases per 100000 . However, during the period June to August 2009, this district witnessed an unusual outbreak of 90 incident cases reported to the MOPH. In order to identify the associated risk factors of brucellosis during an outbreak and understand its etiology, we conducted the following study.

\section{Methods}

\section{Study design and sample}

A matched case-control study was conducted to determine the associated risk factors for brucellosis in an outbreak in Chouf district of Lebanon in 2009. Brucellosis cases were reported to the epidemiological surveillance unit at the MOPH during the period June to August. Cases were either confirmed (positive blood culture test), probable (Wright test $\geq 1 / 160$ ) or suspected (clinical symptoms and Wright test $<1 / 160)$. All cases were residing in Chouf district. For this study, only the most recent case within the same household was included. Old cases that occurred in the previous years but did

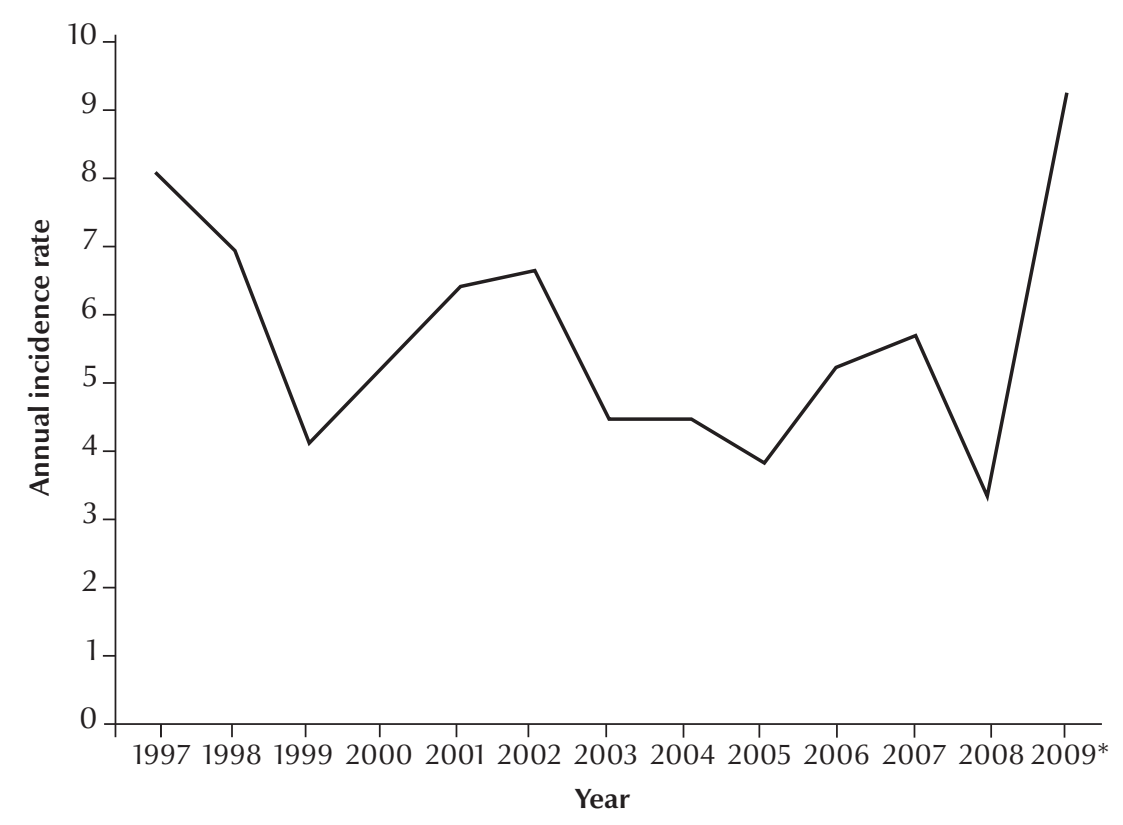

Figure 1 Annual incidence of brucellosis per 100000 inhabitants, Lebanon 1997-2009 (*until October 2009) 
their Wright test during summer 2009 were excluded.

Out of 90 cases, 78 were reached and contacted by the research team. The remaining 12 cases were not reached because they had an incorrect phone number $(n=1)$, had disconnected phone line $(n=1)$, did not answer the phone even after several attempts by the research team $(n=8)$ or did not have a phone number $(n$ $=2)$. Two $(2.6 \%)$ of the 78 subjects reached refused to participate. For this study, 51 cases out of 76 who accepted to participate met the inclusion criteria; 1 case was dropped because matched controls could not be found. Two Brucella-free control subjects were matched to every case according to age, sex and residence. These controls were selected randomly from phone number registries.

\section{Data collection}

A total of 150 subjects (50 cases, 100 controls) answered a structured questionnaire that included 10 items on sociodemographic variables (e.g. educational level, crowding index, family income), 21 items about exposure to Brucella (e.g. During the past 2 months, have you ever had any contact with raw meat? Does your current/previous job require contact with animals or animal products?), 4 items on history of brucellosis (e.g. Have you ever had brucellosis? Has anyone from your family had brucellosis?), 26 items on disease and symptoms (e.g. When did you have your first contact with health care? What were the reasons of delay of seeking health care, if applicable? Did you suffer from chills? Did you experience general malaise?), and 15 items on knowledge, attitudes and behaviour (e.g. Brucellosis is transmitted through raw cheese consumption; I make sure that milk is boiled before drinking it; How do you boil milk?).

The questionnaire was pilot tested on $3 \mathrm{MOPH}$ employees prior to data collection. Data were collected via phone interviews after obtaining the oral consent from subjects, and then entered using Epidata, version 3.1 software.

\section{Ethical considerations}

Since the primary intent of this project was to detect the risk factors associated with the outbreak, in order to prevent its spread and mitigate its impact, this study was carried out urgently without waiting to seek ethical approval from an institutional review board [19]. Nevertheless, all ethical guidelines for research involving human subjects were adhered to. Respect for persons was preserved and oral consent was obtained after informing the subjects about the aim of the study, that their anonymity and confidentiality of data would be maintained, and that they were free to withdraw from the interviews. They were also informed about their choice not to answer questions that they might consider as sensitive (e.g. family income and crowding index). Children under age 12 years were not interviewed, instead their mothers were given the questionnaires.

\section{Data analysis}

Each questionnaire was coded before data entry. Descriptive statistics [means with standard deviations (SD) or frequency distributions] on age, sex, education and family income were calculated. Bivariate analyses were performed on hypothesized risk factors. Variables with $P$-values $\leq 0.10$ in the bivariate analysis were included in a multivariate conditional logistic regression model. Matched odds ratios (MOR) and their corresponding 95\% confidence intervals (CI) along with the $P$-values were reported. Significance was set at the 5\% level. All analyses were done using SPSS, version 16, and STATA, version 10. Maps were generated using the World Health Organization health mapper software.

\section{Results}

The reporting of 90 incident cases of brucellosis to the MOPH during June to August 2009 was a clear indication of an outbreak as compared with the number of incident cases from the same area since January 2008 (Figure 2). The incidence increased from 0.6-3.6 cases per 100000 in the earlier years to 54.3 cases per 100 000. According to the case definition, $6.0 \%$ of cases were confirmed, $56.0 \%$ were probable and $38.0 \%$ were suspected.

The mean age of these cases was 24 (SD 20) years, range 2-74 years. The majority were males $(56.0 \%)$ and from families with monthly income ranging between 1-2 million Lebanese lira (US\$ 667-1333) (57.1\%). Cases were geographically distributed over 21 villages of Chouf district, concentrated in 2 main villages (32.0\%). The most commonly reported symptoms were fever (94.4\%), general malaise (87.5\%), nocturnal sweating (85.5\%), chills (81.4\%), anorexia (75.7\%), arthralgia (72.9\%), in addition to headache $(69.1 \%)$ and weight loss (57.3\%). Moreover, more than $40.0 \%$ of cases experienced delay in seeking proper medical care, most of which was attributed to being misdiagnosed at their primary health care contact (> 60.0\%). Among those included in the case-control study, there were no significant differences in sociodemographic characteristics or family history of the disease between cases and controls (Table 1).

Regarding knowledge of brucellosis, 48 out of 50 cases had ever heard about the disease, compared with only 34 out of 100 controls. A total of 46 cases and 27 controls correctly answered at least 3 out of 6 knowledge questions about the disease. Almost all of those 34 controls knew about transmission via raw milk (91.2\%) and raw cheese (88.2\%) consumption as compared with $70.8 \%$ and $85.4 \%$ of cases respectively. The most common misconception was the oralfecal human to human transmission, 


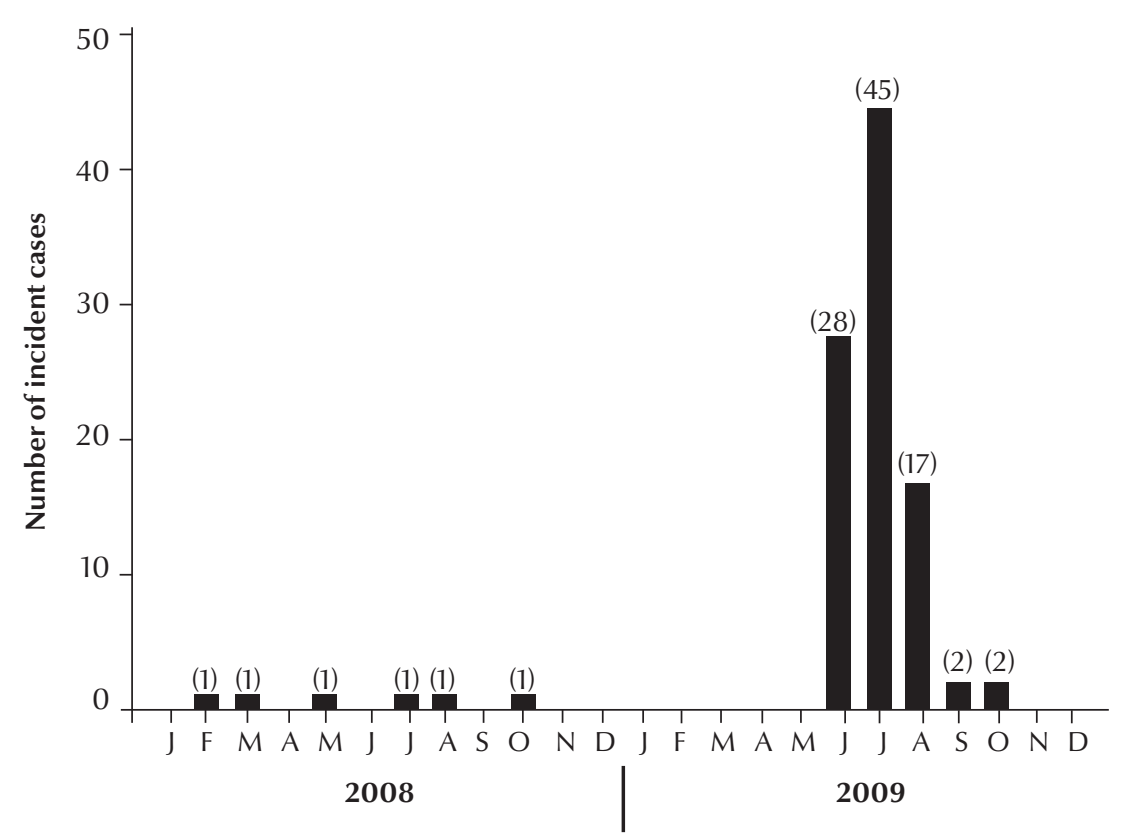

Figure 2 Monthly number of reported cases of brucellosis, Chouf, Lebanon, January 2008-October 2009

where only 9 out of 34 knew that it is not transmitted via this route (26.5\%). This misconception was also prevalent among cases (52.1\%).

At the bivariate level, the incidence of brucellosis was significantly associated with consuming raw cheese in the past 2 months; consuming raw meat in the past 2 months; self-preparing consumed dairy products; and consuming animal products from a reliable source, while believing that gloves should always be put on when in contact with animals or animal products showed borderline significance (Table 2). Other attitudes and behaviours were comparable between cases and controls, such as consumption of powdered milk and belief that domestic animals should be always vaccinated $(P>0.05)$. Exposure to other risk factors such as being in contact with unvaccinated animals; living in proximity to a stable or farm; cleaning farms; or performing farming activities were not significantly different between cases and controls (data not shown). In the final multivariate model, consumption of raw or unprocessed cheese was the only risk factor for brucellosis $(\mathrm{OR}=29.5)$, while believing that gloves should be put on when in contact with animals or animals products and self-preparing consumed dairy products were protective factors $(\mathrm{OR}=$ 0.08 and 0.13 respectively). The other 2 variables considered-consumption of raw meat in the past 2 months and getting animal products from a reliable source - were not associated with brucellosis (Table 2, multivariate analysis). In fact, we observed a strong confounding between consuming raw meat in the past 2 months and self-preparing the consumed dairy product. The introduction of the latter variable to the multivariate model made the first variable lose its statistical significance.

\section{Discussion}

Several studies on brucellosis have been conducted in many endemic Mediterranean countries to determine its different risk factors $[5,7,20-23]$. This study showed some of the many predisposing factors for brucellosis which have been previously identified, such as raw cheese and raw meat consumption, a cultural practice in many Mediterranean countries $[24,25]$, were significant risk factors for brucellosis infection. Moreover, selfpreparing dairy products at home versus purchasing these from supermarket, farms or street vendors seemed to act as a negative confounding factor; $79.6 \%$ of cases versus $16.0 \%$ of controls were eating raw cheese purchased mainly from supermarkets, farms or street vendors and not self-prepared. Moreover, this confounding factor eliminated the significance of the variable "raw meat consumption in the past 2 months", as a large proportion of cases were practising both risk behaviours; of those who were consuming raw meat $85 \%$ were getting their dairy products from supermarkets, farms, or street vendors versus $25 \%$ of controls.

No significant association was detected with yoghurt and raw goat cheese consumption (data not shown). This may be explained by the fact that Brucella spp. are sensitive to the low $\mathrm{pH}$ of yoghurt [5] and that raw goat cheese or serdali cheese is usually self-prepared locally by village people and not bought from supermarkets or farms.

Occupation, family income and educational level were not significant predictors of brucellosis in this outbreak, contrary to what other studies had demonstrated $[5,26,27]$. This can be explained by the fact that, since the controls were case-matched according to place of residency, cases and controls had similar socioeconomic status. Moreover, animal-related occupations are not prevalent in Chouf district, and the infection was not associated with direct contact with animals or animal products but with raw animal product consumption.

No significant differences were found between controls and cases in their attitudes and behaviours, except for the belief that gloves should be always put on whenever there is contact with animals or animal products. On the other hand, both cases and 


\begin{tabular}{|c|c|c|c|c|c|}
\hline \multirow[t]{2}{*}{ Characteristic } & \multicolumn{2}{|c|}{ Cases } & \multicolumn{2}{|c|}{ Controls } & \multirow[t]{2}{*}{$P$-value } \\
\hline & No. & $\%$ & No. & $\%$ & \\
\hline \multicolumn{6}{|l|}{ Sex } \\
\hline Male & 28 & 56.0 & 56 & 56.0 & \multirow[t]{2}{*}{1.0} \\
\hline Female & 22 & 44.0 & 44 & 44.0 & \\
\hline Mean age in years $(S D)$ [range] & \multicolumn{2}{|c|}{$24.0(19.2)[2-74]$} & \multicolumn{2}{|c|}{24.9 (19.5) [1-86] } & 0.91 \\
\hline \multicolumn{6}{|l|}{ Marital status } \\
\hline Single & 33 & 66.0 & 69 & 69.0 & \multirow{4}{*}{0.72} \\
\hline Married & 17 & 34.0 & 29 & 29.0 & \\
\hline Widowed & 0 & 0.0 & 1 & 1.0 & \\
\hline Divorced & 0 & 0.0 & 0 & 0.0 & \\
\hline \multicolumn{6}{|l|}{ Education } \\
\hline Elementary or below & 25 & 50.0 & 32 & 32.7 & \multirow{3}{*}{0.12} \\
\hline Intermediate & 9 & 18.0 & 24 & 24.5 & \\
\hline Secondary/university & 16 & 32.0 & 42 & 42.8 & \\
\hline \multicolumn{6}{|l|}{ Family income (million LL/month) } \\
\hline$\leq 1$ & 18 & 36.7 & 41 & 43.2 & \multirow[t]{3}{*}{0.50} \\
\hline $1-2$ & 28 & 57.1 & 45 & 47.4 & \\
\hline$>2$ & 3 & 6.1 & 9 & 9.5 & \\
\hline \multicolumn{6}{|l|}{ Crowding index ${ }^{a}$} \\
\hline High (> 2 people per room) & 2 & 4.0 & 9 & 9.0 & $0.34^{\mathrm{b}}$ \\
\hline Family history of brucellosis & 2 & 4.0 & 5 & 5.0 & $1.0^{\mathrm{b}}$ \\
\hline \multicolumn{6}{|l|}{ Occupation } \\
\hline Currently working & 9 & 18.0 & 23 & 23.0 & \multirow{6}{*}{0.67} \\
\hline Was working 4 months ago & 3 & 6.0 & 1 & 1.0 & \\
\hline Not working & 3 & 6.0 & 7 & 7.0 & \\
\hline Retired & 1 & 2.0 & 3 & 3.0 & \\
\hline Student & 26 & 52.0 & 53 & 53.0 & \\
\hline Housewife & 7 & 14.0 & 12 & 12.0 & \\
\hline \multicolumn{6}{|l|}{ Type of occupation } \\
\hline Animal-related & 0 & 0.0 & 3 & 12.5 & \multirow{2}{*}{$0.53^{b}$} \\
\hline Non-animal related & 12 & 100.0 & 21 & 87.5 & \\
\hline
\end{tabular}

${ }^{a}$ Crowding index: number of individuals per room excluding kitchen, bathroom, storage room, and balcony; ${ }^{b}$ Fisher exact test.

$S D=$ standard deviation $; L=$ Lebanese lira .

controls (> $50 \%$ of the total sample) were practising an unintended risky behaviour by boiling and pasteurizing milk at the household level. This milk was mainly brought from shepherds living in the same district and its consumption did not appear to be a risk factor in this outbreak. In fact, the source of contamination was then discovered to be from animal products imported from dairy plants from other regions in Lebanon.
Knowledge about the disease was low among the controls as only few of them had ever heard about brucellosis. In addition, a large number of participants (cases and controls) falsely believed that fecal-oral human transmission was possible.

This case-control study had a number of limitations. The first limitation was that no clinical testing was performed on controls to confirm that controls were free of Brucella spp., relying only on their self-reported information after asking them if they ever had brucellosis. However, it is unlikely that controls were false negatives or asymptomatic since Chouf is not an endemic area for brucellosis. A second limitation is the recall bias, whereby cases may recall more accurately their exposure 2 months before their onset of disease as compared with controls. Thirdly, children aged $0-12$ years were not directly interviewed by the research team due to ethical reasons. Instead, mothers 


\begin{tabular}{|c|c|c|c|c|c|c|c|c|}
\hline \multirow[t]{2}{*}{ Variable } & \multicolumn{2}{|c|}{ Cases } & \multicolumn{2}{|c|}{ Controls } & \multicolumn{2}{|l|}{ Bivariate } & \multicolumn{2}{|c|}{ Conditional multivariate } \\
\hline & No. & $\%$ & No. & $\%$ & Crude OR $(95 \% \mathrm{CI})$ & $P$-value & Adjusted OR (95\% CI) & $P$-value \\
\hline $\begin{array}{l}\text { Consumes animal products from } \\
\text { a reliable source }\end{array}$ & 42 & 84.0 & 92 & 96.8 & $0.21(0.06-0.79)$ & 0.01 & $0.33(0.04-3.07)$ & 0.33 \\
\hline $\begin{array}{l}\text { Believes that gloves should always } \\
\text { be used when in contact with } \\
\text { animals or animal products }\end{array}$ & 33 & 70.2 & 82 & 84.5 & $0.46(0.21-1.04)$ & 0.06 & $0.08(0.01-0.52)$ & 0.01 \\
\hline $\begin{array}{l}\text { Consumed raw cheese in past } 2 \\
\text { months }\end{array}$ & 39 & 79.6 & 16 & 16.0 & $20.0(6.12-65.2)$ & $<0.001$ & $29.5(4.16-09)$ & 0.001 \\
\hline $\begin{array}{l}\text { Consumed raw meat in past } 2 \\
\text { months }\end{array}$ & 20 & 40.8 & 21 & 21.0 & $3.00(1.32-6.84)$ & 0.009 & $2.49(0.46-13.5)$ & 0.29 \\
\hline $\begin{array}{l}\text { Source of dairy products (self- } \\
\text { prepared versus other }{ }^{\mathrm{a}} \text { ) }\end{array}$ & 8 & 16.0 & 48 & 57.1 & $0.15(0.06-0.39)$ & $<0.001$ & $0.13(0.02-0.84)$ & 0.03 \\
\hline
\end{tabular}

${ }^{a}$ Other includes supermarkets, farms and street vendors.

$O R=$ odds ratio; $C I=$ confidence interval.

reported their children's exposure, thus creating a possible information bias to the results. Finally, the small sample size resulted in large confidence intervals in some instances, which was inevitable due to time restraints and the urgent need to reveal the potential associated factors. Despite these limitations, most of which are common in case-control studies, the results highlight the risk factors associated with this outbreak.

This study highlights the need to enhance food safety standards and elevate monitoring levels in the Lebanese food industry. It also calls attention to the risk factors that can be modified to control future outbreaks of brucellosis. Increasing public awareness and knowledge about the disease and its symptoms, and the correct methods of pasteurization of milk and dairy products, in addition to proper ways of handling raw meat at home through the use of gloves, are important measures for effective containment and control.

\section{Acknowledgements}

The authors thank the Ministry of Public Health for allowing the conduct of this research project. They also thank the epidemiological surveillance unit staff in general, and Ms Yolla Baddour and Ms Alia Nasreddine in specific, for providing names and contact information for the identified cases of brucellosis.

\section{Funding: None.}

Competing interests: None declared.

\section{References}

1. Boschiroli $\mathrm{ML}$, Foulongne $\mathrm{V}, \mathrm{O}^{\prime}$ Callaghan D. Brucellosis: a worldwide zoonosis. Current Opinion in Microbiology, 2001, 4:58-64.

2. Brucellosis. Ames, lowa, Center for Food Security and Public Health, lowa State University, 2007 (http://www.cfsph.iastate. edu/Factsheets/pdfs/brucellosis.pdf, accessed 19 September, 2013).

3. Corbel MJ. Brucellosis in humans and animals. Geneva, World Health Organization, Food and Agriculture Organization of the United Nations and World Organization for Animal Health, 2006.

4. Mesner $\mathrm{O}$ et al. The many faces of human-to-human transmission of brucellosis: Congenital infection and outbreak of nosocomial disease related to an unrecognized clinical case. Clinical Infectious Diseases, 2007, 45:e135-e140.

5. Al-Shamahy HA, Whitty CJ, Wright SG. Risk factors for human brucellosis in Yemen: a case control study. Epidemiology and Infection, 2000, 125:309-313.

6. El-Ansary EH et al. Brucellosis among animals and human contacts in eastern Sudan. SaudiMedical Journal, 2001, 22:577579.
7. Al-Ani FK et al. Human and animal brucellosis in Jordan between 1996 and 1998: a study. Revue Scientifique et Technique, 2004, 23:831-840.

8. Refai M. Incidence and control of brucellosis in the near east region. Veterinary Microbiology, 2002, 90:81-110.

9. Heymann DLM, ed. Control of communicable diseases manual, 18th ed. Washington DC, American Public Health Association, 2004.

10. Annual report 2009. Beirut, Lebanon, Epidemiological Surveillance Unit, Ministry of Public Health, 2009.

11. Ghosn $\mathrm{N}$ et al. Electronic surveillance of outbreaks in Lebanon. BMC Proceedings, 2008, 2(Suppl. 3):S2.

12. Kalaajieh WK. Epidemiology of human brucellosis in Lebanon in 1997. Medecine et Maladies Infectieuses, 2000, 30:43-46.

13. Tohme A et al. Brucellose humaine au Liban. Étude clinique et thérapeutique de 88 patients [Human brucellosis in Lebanon. Clinical features and therapeutic responses in 88 patients]. Le Journal Medical Libanais, 2004, 52:149-155.

14. Tohme A et al. Brucellose humaine. Étude rétrospective de 63 cas observes au Liban [Human brucellosis. Retrospeca 
tive studies of 63 cases in Lebanon]. Presse Medicale, 2001, 30:1339-1343.

15. Traboulsi R, Uthman I, Kanj SS. Prepatellar Brucella melitensis bursitis: case report and literature review. Clinical Rheumatology, 2007, 26:1941-1942.

16. Dakdouki GK, Al Awar GN. Brucella prostatic abscess: first case report. Scandinavian Journal of Infectious Diseases, 2005, 37:692-694.

17. Koussa S, Chemaly R. Neurobrucellosis presenting with diffuse cerebral white matter lesions. European Neurology, 2003, 50:121-123.

18. Alwan $\mathrm{N}$ et al. Resistance of Brucella abortus isolated from Lebanese dairy-based food products against commonly used antimicrobials. Dairy Science and Technology, 2010, 90:579-588.

19. Coughlin S. Ethical issues in epidemiological research and public health practice. Emerging Themes in Epidemiology, 2006, 3:16. doi: 10.1186/1742-7622-3-16.

20. Meky FA et al. Epidemiology and risk factors of brucellosis in Alexandria governorate. Eastern Mediterranean Health Journal, 2007, 13:677-685.
21. Sofian $\mathrm{M}$ et al. Risk factors for human brucellosis in Iran: a case-control study. International Journal of Infectious Diseases, 2008, 12:157-161.

22. Husseini AS, Ramlawi AM. Brucellosis in the West Bank, Palestine. Saudi Medical Journal, 2004, 25:1640-1643.

23. Al-Majali AM, Shorman M. Childhood brucellosis in Jordan: prevalence and analysis of risk factors. International Journal of Infectious Diseases, 2009, 13:196-200.

24. Malik GM. A clinical study of brucellosis in adults in the Asir region of southern Saudi Arabia. American Journal of Tropical Medicine and Hygiene, 1997, 56:375-377.

25. Tanir G, Tufekci SB, Tuygun N. Presentation, complications, and treatment outcome of brucellosis in Turkish children. Pediatrics International, 2009, 51:114-119.

26. Bikas $\mathrm{C}$ et al. Epidemiology of human brucellosis in a rural area of north-western Peloponnese in Greece. European Journal of Epidemiology, 2003, 18:267-274.

27. Kozukeev TB et al. Risk factors for brucellosis-Leylek and Kadamjay districts, Batken Oblast, Kyrgyzstan, January-November, 2003. Morbidity and Mortality Weekly Report, 2006, 55 (Suppl. 1):31-34. 